\title{
Pulsus alternans induced by glyceryl trinitrate paste in a patient with alcoholic cardiomyopathy
}

\author{
P. A. N. CHANDRARATNA, E. LANGEVIN, AND J. LANGEVIN \\ From the Division of Cardiology, University of Oklahoma Health Sciences Center, \\ Oklahoma City, Oklahoma, USA
}

SUMMARY Application of a small dose of glyceryl trinitrate paste $(0.25 \mathrm{in})$ resulted in severe left ventricular dysfunction with the appearance of pulsus alternans in a patient with alcoholic cardiomyopathy. The echocardiogram showed a reduction in the amplitude and velocity of motion of the left ventricular posterior wall on alternate beats. Leg elevation promptly reversed the pulsus alternans, and the echocardiographic abnormality. Glyceryl trinitrate paste should be used with caution and under close supervision in patients with liver dysfunction.

Reduction of afterload by vasodilator therapy has been shown to be an effective means of treating refractory cardiac failure (Mikulic et al., 1975; Kovick et al., 1976; Mantle et al., 1976). Glyceryl trinitrate paste has a prolonged duration of action and has been shown to be a useful agent in the treatment of heart failure (Reichek et al., 1974; Taylor et al., 1976). Because of the widespread use of this agent it is important to recognise its possible adverse effects (Come and Pitt, 1976). This report describes a patient with alcoholic cardiomyopathy in whom an acute deterioration of left ventricular function was observed after the application of a small dose of glyceryl trinitrate.

\section{Case report}

A 34-year-old white man was admitted with complaints of dyspnoea and swelling of his legs. He admitted to having consumed $\frac{1}{2}$ to 1 pint of vodka each day or similar hard liquor for over 8 years. On examination, he was orthopnoeic, and had bilateral ankle oedema. His jugular venous pressure was raised $10 \mathrm{~cm}$ above the sternal angle at $45^{\circ}$. The blood pressure was $104 / 88 \mathrm{mmHg}$ and his pulse was $124 /$ minute and regular. The maximum impulse was in the sixth intercostal space in the anterior axillary line. There was a loud $S_{3}$ gallop. Basal râles were present. The liver was palpable $10 \mathrm{~cm}$ below the right costal margin and was tender. The span of the liver was $16 \mathrm{~cm}$ by percussion. The spleen was not palpable. The neurological examination was within normal limits.

The electrocardiogram showed left ventricular hypertrophy, and nonspecific ST-T changes. His chest $x$-ray film showed pronounced cardiomegaly and changes consistent with pulmonary oedema. The echocardiogram disclosed conspicuous ventricular dilatation (left ventricular end-diastolic dimension $=7 \mathrm{~cm}$ ) with poor wall motion. The left atrium was enlarged. The serum electrolytes were normal. The total bilirubin was $54.7 \mu \mathrm{mol} / 1(3.2 \mathrm{mg} / 100 \mathrm{ml})$; direct bilirubin $32.5 \mu \mathrm{mol} / 1(1.9 \mathrm{mg} / 100 \mathrm{ml})$; alkaline phosphatase, $160 \mathrm{mU} / \mathrm{ml}$ (normal range 30 to $115 \mathrm{mU} / \mathrm{ml}$ ); $\mathrm{LDH}, 375 \mathrm{mU} / \mathrm{ml}$ (normal range 100 to $225 \mathrm{mU} / \mathrm{ml}$ ); aspartate aminotransferase (AST; SGOT), $207 \mathrm{mU} / \mathrm{ml}$ (normal range 7.5 to $60 \mathrm{mU} / \mathrm{ml} ; \mathrm{CK}, 74 \mathrm{IU} / 1$ (normal range 50 to $180 \mathrm{IU} / 1)$; the prothrombin time was 14.2 with a control of 10.9 seconds. The liver function tests done after control of cardiac failure were as follows: AST(SGOT) $247 \mathrm{mU} / 100 \mathrm{ml}$, serum alkaline phosphatase $151 \mathrm{mU} / 100 \mathrm{ml}, \mathrm{LDH}, 298 \mathrm{mU} / 100 \mathrm{ml}$, total bilirubin $27.4 \mu \mathrm{mol} / 1(1.6 \mathrm{mg} / 100 \mathrm{ml})$, direct bilirubin $17 \cdot 1 \mu \mathrm{mol} / 1(1.0 \mathrm{mg} / 100 \mathrm{ml})$, and prothrombin time 16.4 seconds (control, 10.0).

His congestive cardiac failure responded well to salt restriction, digitalis, and diuretics. $\mathrm{He}$ was discharged on the above medications and advised to refrain from alcohol. He was seen in the outpatient clinic two months later. Though symptomatically improved he continued to have shortness of breath on exertion and his chest $x$-ray film showed pulmonary venous congestion. A trial of therapy with glyceryl trinitrate paste was, therefore, advised.

His resting blood pressure was $100 / 80 \mathrm{mmHg}$ and his pulse was $103 /$ minute. He was seated in bed with his head tilted up $45^{\circ}$. One quarter inch $(0.25$ in) of glyceryl trinitrate paste was applied over a $6^{\prime \prime} \times 6^{\prime \prime}$ area of skin over the abdomen, covered 
with saran wrap, and taped on all four sides. Pulse and blood pressure were recorded every 15 minutes. Thirty minutes after the application of glyceryl trinitrate a sharp fall in the blood pressure to $74 / 60$ $\mathrm{mmHg}$ was observed. His pulse was $120 /$ minute with a distinct pulsus alternans, every other beat being barely palpable. The systolic blood pressure of the strong beat was $74 \mathrm{mmHg}$ and that of the weak beat was $38 \mathrm{mmHg}$. The patient did not feel dizzy and had not noticed any other symptoms. An echocardiogram taken at that time showed that the amplitude and velocity of left ventricular posterior wall motion was much reduced on every other beat. The carotid pulse showed a striking reduction of amplitude of every other beat, corresponding to the weak beats on the posterior wall echocardiogram. The patient was laid flat, his legs raised, and the glyceryl trinitrate paste removed. The blood pressure increased to $104 / 76 \mathrm{mmHg}$ a few seconds after leg elevation and the pulsus alternans disappeared. The echocardiogram done at this time showed regular left ventricular posterior wall contractions. The carotid pulse showed a disappearance of the alternans pattern. After 40 minutes the standing blood pressure was $104 / 64 \mathrm{mmHg}$.

\section{Discussion}

This patient clearly showed a deterioration of left ventricular function as evidenced by the development of pulsus alternans after the application of glyceryl trinitrate paste. It is interesting to speculate why this occurred. Our patient had evidence of liver dysfunction on admission. This could have been caused by alcoholic hepatitis or passive venous congestion of the liver. Though improvement in the liver function tests was noted after treatment of his failure, some tests remained abnormal. This suggested some degree of underlying liver disease. Patients with liver disease and alcoholism have cutaneous vasodilatation which may facilitate the absorption of glyceryl trinitrate paste. Our patient did show conspicuous cutaneous vasodilatation as evidenced by a very plethoric skin. Furthermore, in the presence of liver disease glyceryl trinitrate is probably not inactivated as rapidly as in the normal subject. Rapid cutaneous absorption and reduced rate of inactivation probably resulted in high blood levels of glyceryl trinitrate in our patient. This probably caused much arteriolar and venous dilatation, with a consequent fall in the blood pressure and cardiac output. The heart rate increased from 103 to 120 beats per minute. These factors probably resulted in pulsus alternans. The echocardiogram clearly showed a reduction in amplitude and velocity of motion of the left ventricular posterior wall on alternate beats. This abnormality disappeared after leg elevation.

One may argue that he had a low left atrial pressure before treatment with glyceryl trinitrate. The presence of pulmonary venous congestion on the chest $x$-ray film taken on the day of application of glyceryl trinitrate paste precludes such an argument. Thus, his left ventricular filling pressure was probably high before the treatment. The small amount of glyceryl trinitrate was sufficient to produce severe venous dilatation and consequent reduction of preload to place him in the steep ascending limb of the Starling curve, with a resultant fall in cardiac output.

It is of interest that his hypotension and pulsus alternans were promptly corrected by leg elevation. This suggests that his hypotension and left ventricular dysfunction (manifested as pulsus alternans) were the direct result of pronounced venous pooling which produced a drastic reduction in preload. It is noteworthy that the patient remained asymptomatic in spite of considerable haemodynamic deterioration.

We conclude that the dose of glyceryl trinitrate paste should be carefully adjusted in patients with hepatic dysfunction. Monitoring of blood pressure, heart rate, and echocardiographic left ventricular wall motion may be effective in avoiding serious sequelae.

\section{References}

Come, P. C., and Pitt, B. (1976). Nitroglycerin-induced severe hypotension and bradycardia in patients with acute myocardial infarction. Circulation, 54, 624-628.

Kovick, R., Tillisch, J. H., Berens, S. C., Bramowitz, A. D., and Shine, K. I. (1976). Vasodilator therapy for chronic left ventricular failure. Circulation, 53, 322-328.

Mantle, J. A., Russell, R. O., Moraski, R. E., and Rackley, C. E. (1976). Isosorbide dinitrate for the relief of severe heart failure after myocardial infarction. American fournal of Cardiology, 37, 263-268.

Mikulic, E., Franciosa, J. A., and Cohn, J. N. (1975). Comparative hemodynamic effects of chewable isosorbide dinitrate and nitroglycerin in patients with congestive heart failure. Circulation, 52, 477-482.

Reichek, N., Goldstein. R. E., Redwood, D. R., and Epstein, S. E. (1974). Sustained effects of nitroglycerin ointment in patients with angina pectoris. Circulation, 50, 348-352.

Taylor, W. R., Forrester, J. S., Magnusson, P., Takano, T., Chatterjee, K., and Swan, H. J. (1976). Hemodynamic effects of nitroglycerin ointment in congestive heart failure. American fournal of Cardiology, 38, 469-473.

Requests for reprints to Dr P. A. N. Chandraratna, Division of Cardiology, S-10, Veterans Administration Hospital, 5901 East Seventh Street, Long Beach, California 90822, USA. 